\title{
Supervisory Support Received by EFL Student Teachers during Practicum: The Missing Link
}

\author{
Morshed Salim Al-Jaro* \\ Seiyun University, Hadhramout, Yemen \\ maljaro@seiyunu.edu.ye \\ Adelina Asmawi \\ University of Malaya, Malaysia
}

Abdul-Qader Khleel Abdul-Ghafour

Queen Arwa University, Sana'a, Yemen

DOI: http://doi.org/ 10.36892/ijlls.v2i4.437

\begin{tabular}{|c|c|}
\hline $\begin{array}{l}\text { Received: } \\
\text { 05/11/2020 }\end{array}$ & $\begin{array}{l}\text { Abstract } \\
\text { This study investigates the role of supervisory support for assisting the EFL }\end{array}$ \\
\hline $\begin{array}{l}\text { Accepted: } \\
\text { 06/12/2020 }\end{array}$ & $\begin{array}{l}\text { student teachers to perform better during practicum. It also aims at identifying } \\
\text { the barriers of effective supervision during teaching practicum. The study } \\
\text { adopts the qualitative research design using a multiple case study. Semi- } \\
\text { structured interviews are developed to collect data from four student teachers }\end{array}$ \\
\hline $\begin{array}{l}\text { Keywords: } \\
\text { Pedagogical } \\
\text { practices; practicum; } \\
\text { supervisory support; } \\
\text { teaching practice }\end{array}$ & $\begin{array}{l}\text { and their supervisors during their teaching practices at local secondary } \\
\text { schools in Yemen. Four emerging themes are developed from the thematic } \\
\text { analysis of the data including the supervisory support on lesson planning, } \\
\text { teaching strategies, classroom management and the number of observations. } \\
\text { The findings reveal that the participating student teachers received insufficient } \\
\text { support and guidance from their panel supervisors which limit their } \\
\text { pedagogical practices during practicum. The findings also highlight some } \\
\text { barriers to effective supervision due to some restrictions. The study provides } \\
\text { practical implications for EFL teacher education program administrators and } \\
\text { developers to reconsider the supervision plan so as to contribute towards } \\
\text { professional teaching practices at schools during practicum in Yemen. }\end{array}$ \\
\hline
\end{tabular}

\section{INTRODUCTION}

Teaching practicum is a significant component of any teacher preparation program and is considered the essential learning experience for beginning teachers (Canh, 2014; Svojanovsky, 2017; Valencia, Martin, Place, \& Grossman, 2009). It is a duration when novice teachers go to schools to teach and gain experience during their training under the guidance and supervision of expert teachers (Mukeredzi \& Mandrona, 2013). This preparation stage is, therefore, crucial to create a difference in the novice teachers' practice where "fully prepared and certified teachers are generally better rated and more successful with students than teachers without this preparation" (Darling-Hammond (2000, p. 167). Yet, the intended purpose of teaching practicum is to provide novice teachers with opportunities to obtain practical skills and knowledge needed to function as effective language teachers.

Supervision provided by mentor teachers and supervisors is also fundamental to guide and promote the learning needs of novice teachers during teaching practicum. Therefore, the 
availability and professionalism of those mentors and supervisors are required to encourage novice teachers to learn from their practical experience (Crasborn et al., 2008).

\section{THEORETICAL BACKGROUND}

Vygotsky's Sociocultural Theory (henceforth SCT) of Learning (1978, 1986) describes learning as a social process that is influenced by historical, cultural, and social factors and occurs within social interactions (Vygotsky, 1978; Wertsch, 1991; Yassin, Razak, \& Maasum, 2019). It is "a dynamic social activity that is situated in physical and social contexts, and is distributed across persons, tools, and activities" (Johnson, 2006, p. 1). The basic assumption in SCT which makes it distinctive from behavioral or other cognitive theories is that the psychological structures are formed as a result of interaction and the higher level of human cognition in the individual and has its origins in social life (Behroozizad, Nambiar, \& Amir, 2014; Johnson, 2006). The ideas introduced in SCT have a great influence on the field of education. It has a holistic view towards learning and regards meaning as the fundamental part for a teaching unit in which skills and knowledge should be presented in all its complex forms (Turuk, 2008). The learners are expected to be the makers of active meaning in the learning process. Ellis (2000) argues that learning does not happen through interaction, but it is raised in interaction. When learners are involved in a certain task under the assistance of another peer or the expert, they internalize the way to carry out the task by themselves. In this way, the social interaction is believed to mediate learning (Fahim \& Haghani, 2012) and help learners scaffold the new tasks (Ellis, 2000).

In fact, the field of second language learning research has widely used and referred to SCT (Aimin, 2013). Therefore, adopting such theory would offer a theoretical base that learning is enhanced when the members of a social practice community actively interact and participate in constructing the learning process (Gheisari \& Jamali, 2014).

Although SCT of learning is basically centred on the child's development, it has been widely used and referred to when discussing learning and teaching of second and foreign languages. Therefore, researches attempt to bridge the gap between the theory's concepts and its use in the learning and teaching setting. For instance, Ohta (2001) conceptualizes the Zone of Proximate Development (ZPD) for teaching and learning second language as the distance between the actual and potential development levels which are respectively determined by the individual linguistic production and production formed collaboratively with assistance. Similarly, ZPD could be germane to the teaching practice development. This is important as novice teachers encounter some challenges during classroom teaching practices which are not easy to solve without receiving social assistance from the experts. Such social assistance should be maximized to solve student teachers' teaching problems and promote their knowledge and ability to teach. Thus, through supervision for the problem-solving activities, novice teachers would be cognitively developed, and the potential level of development would be accomplished. They, therefore, can teach without the assistance and support of their supervisors one day.

Scaffolding, in the other hand, which is the assistance and support that occurred temporarily in ZPD would enable the learner to internalize and regulate a taught concept (Van Lier, 2004). Based on the Vygotskian notion of ZPD, the social transaction and interaction form the fundamental means of education that enable learners entering into the culture via induction by more knowledgeable members. Thus, through effective scaffolding, the potential level of development of ZPD could be extended, and learners might be able to reach what they are thought to be capable of (Hammond, 2002).

With regard to the ways the learner gets scaffolded in teaching, a number of scholars have emphasized the intended role of an expert to guide the learner's learning and development and assist them to undertake tasks or form new understandings on their own 
(Hammond, 2002; Darling-Hammond and Baratz-Snowden, 2005). Others have argued that teachers should be aware of when and how scaffolding should occur. For example, Hammond (2002) stresses the importance of timely support in which teachers provide their learners with support and assistance at the point of need which requires them to have a good understanding of the level of their learners at the beginning of an activity. In terms of the quality of support, Van Lier (1996) argues that support should be contingent in which teachers are able to judge the need and quality of support required by learners. They should be also able to relate it to the way it is paced on the basis of learners' developing understandings. Eventually, whatever the ways and means are, the desirable intent is to enhance the learners' development and achieve the potential level of development.

Therefore, student teachers are supposed to receive assistance and support during their social interactions with mentors and supervisors who guide and support them during their practical teaching. Supervisors are supposed to observe and evaluate the student teachers' teaching performance.

Overall, SCT of learning, especially the concept of ZPD and its implications for scaffolding and mediation is very important to this study as it suits its scope. During practicum in the field and when student teachers start teaching at schools, they need to observe their cooperating teachers before they start the actual teaching practices and take the whole teaching task of the cooperating teachers. They can gradually start teaching under the guidance and assistance of those cooperating teachers and university supervisors. Through their social interaction with supervisors during post observation sessions and through the comments they receive, their pedagogical practices could be enhanced, and they would be able to reflect on their teaching practices and perform better next classes.

\section{LITERATURE REVIEW}

\subsection{Supervision}

Scholars asserted the importance of practicum supervision in assisting novice teachers to translate into practice what they have learned to improve their professional performance (Farrell, 2007; Richards \& Crookes, 1988; Wallace, 1991). The supervisor's role is not only to become a subject matter expert and to focus only on pedagogical strategies for teaching a particular discipline, but also to lead a subject matter for student teachers. Wallace (1991) added that novice teachers need to attend departmental meetings and in-service activities at school and, with their mentors, could participate in content-area seminars. Thus, it is better for them to work with a number of experienced teachers rather than with only one teacher.

For a successful teaching practicum, there must be cooperation among all members involved. They have a fundamental role in preparing novice teachers for classroom needs and realities, with teaching methods and subject matter (Tuli, 2009).

Novice teachers and mentors, or cooperating teachers, are considered the cornerstone of teaching practicum as collaboration between them may lead to a successful teaching practice experience (Chien, 2013; Valencia, Martin, Place, \& Grossman, 2009). They spend much time with them and most available for advice during practicum period (Farrell, 2008) and also assist in linking theory to practice (Kecik \& Aydin, 2011). When student teachers are in schools, they take over cooperative teachers' teaching responsibility until practicum ends. Cooperating teachers observe, record, and report on the student teachers' progress and application of knowledge (Duquette, 1994; Endeley, 2014; Merç, 2011). They are also advisors and facilitators to these juniors. At the same time, they arrange and elicit meaning that the student teachers are making of their teaching practices (Clarke, Triggs, \& Nielsen, 2013). Likewise, university supervisors have fundamental roles to ensure the teaching quality 
of student teachers. They observe and evaluate student teachers' pedagogical skills and provide feedback essential for their professional development. They also need to assess and grade these student teachers' performance (Haciomeroglu, 2013).

Several researchers have shown the effectiveness of supervision on the student teachers' teaching practice. For example, Kourieos (2012) applied a qualitative case study to identify the kind of impact mentoring had on student teachers' learning to teach during practicum. Kourieos interviewed 14 student teachers studying at a private university in Cyprus. The results emphasized monitor roles, which moves away from assessing roles to more assisting, mediating roles. The study concluded that supervisors should put more effort into visiting and guiding student teachers during practicum. Instead of just assessing for grading purposes, supervisors should provide as much feedback as possible on their teaching.

Chien (2013) investigated a summer school program for prospective English language teachers in the north-west of United States. The researcher interviewed and observed three prospective teachers who have completed their elementary school teacher certificate. The main findings of her study revealed that the student teachers' engagement in teaching was limited. Also, there was little collaboration between cooperating and prospective teachers. There were also unclear goals of the summer school, and curriculum planning. At the end of the study, she recommended that there should be collaboration between university and elementary schools to improve collaboration between cooperating and prospective teachers, and curriculum design and therefore practicum experience.

Similarly, Cahn (2014) studied five Vietnamese EFL student teachers' experiences during a six-week practicum period. Findings show that the student teachers were strongly affected by their models rather than attempting to apply theories and teaching ideas taught in the teaching programme. For that, Cahn argued that no deep learning took place during the practicum, and that student teachers were not provided with opportunities for interactive learning. This was imputed to the limited interaction between student teachers and their cooperating teachers. Besides, the relationship between the cooperating teachers and the student teachers was hierarchical rather than reciprocal which limited the latter's involvement in the ongoing process of constructing and reconstructing knowledge with cooperating teachers.

\subsection{Supervisor-supervisee relationship}

It is assumed that student teachers should maintain a positive relationship with supervisors to warrant quality-learning outcomes (Lu, 2013). Al Sohbani, (2012) regarded that "Student teachers' relationship with their supervisors, cooperating teachers, and host schools as the most important part of teaching experience" (p. 196). The cooperative teacher, for example, can facilitate (Haciomeroglu, 2013), monitor, guide and evaluate their teaching practices (Hyland \& Lo, 2006). Another type of relationship should be created between the cooperative teachers and the university supervisors. Valencia, Martin, Place and Grossman (2009) argued that many organizing, and monitoring teaching practice problems occur when there is no 'equal' relationship between the school teachers (cooperative teachers) and the university supervisors. That kind of relationship is necessary to build the bridge between the university and the schools (Zeichner, 2010). In fact, all supervisors' roles gradually changed during practicum. They started by being advisors and facilitators, and then, evaluators in the end.

Likewise, Graham (2006) found that the relationships between the two varied based on the context. These relationships were mostly hierarchical therefore, not effective for professional development. Other researchers (e.g., Rodgers and Keil, 2007; Wilson, 2006) asserted on using the collaborative, equal relationships and shared decision making between 
supervisors and supervisees. They argued that through collaborative relationships in the teaching and learning context, the benefits of learning could be fully realized.

In a similar study, Ibrahim (2013) studied the supervisory approach preferred by the student teachers, those used by cooperating teachers and university supervisors, and their significance for teacher development in one UAE university. The study collected quantitative data from 108 student teachers and interview data from 10 university supervisors. The results concluded that student teachers were dissatisfied with directive approach of their university supervisors and wished to have more collaboration and autonomy.

In examining issues and concerns faced by ESL student teachers during practicum, Ali, Othman, and Karim (2014) explored three main areas of concern: implementation of practicum, effect of mentor teachers and faculty supervisor interaction on the effectiveness of the practicum experience, and mentor teachers and faculty supervisors' expectations of student performance during practicum. Findings revealed a noticeable change in student teachers' interaction with their supervisors and mentors, and their expectations on the efficacy of the practicum experience.

Therefore, interaction between supervisors and mentor teachers should be conducted from time to time which would lead to success in teaching practice experience. Establishing such interaction could "afford guidance to the cooperating teachers as they serve as models for student teachers" (Canh, 2014, p. 219).

\subsection{Feedback}

Supervisors' The support offered by supervisors during practicum is mainly appeared in their suggestions, advice and feedback to improve the student teachers' practice and assess their teaching (Copland, 2010) The feedback on teaching practice is considered very important for student teachers to learn to teach effectively. Moody (2009) identifies four key elements for successful teaching practice among which is the constructive feedback. Moody added that student teachers are eager to hone pedagogical skills and strategies, and their main interest is in getting constructive feedback on their teaching practice. In the same vein, Copland (2011) specified five central tasks through which effective feedback could be provided. The first task is self-evaluation where student teachers discuss lessons with supervisors and highlight lesson strengths and weaknesses. The second task is where supervisors critique lessons with suggestions. Next, student teachers can respond to peers' lessons and provide comments on their teaching performance. The fourth task is where the supervisors question student teachers on their lessons. The final task is the clarification stage in which student teachers have a dialogue on their lesson.

Research on practicum feedback has shown that the student teachers can effectively evaluate their own teaching practice and become more reflective of their supervisors' feedback (Graham, 1996, cited in White, 2007). Graham suggested some leading questions to help them reflect on their teaching at the beginning of the feedback session, followed by supervisor comments. Whereas Copland (2011) realized that the dyadic feedback is the common type used where it is often held in groups, with on trainers and a group of trainees. Feedback can also be spoken or written. Black and Wiliam (1998) outlined the benefits of spoken and written feedback in confirming the intended outcome, motivating the student teachers, enabling them to assess their performance and letting them identify the next step. In the same line, Babkie (1998) indicated the importance of both types of feedback. She maintained that both should be given to the student teachers, covering all aspects of their teaching. However, Bain, Mills, Ballantyne, and Packer (2002) argued that written feedback is extremely useful as it allows student teachers to reflect better. Similarly, Ali and Al-Adawi (2013) explored that both spoken and written feedback are important and useful. However, 
the student teachers preferred written feedback because of ease in reference. On the contrary, White (2007) found that spoken feedback was the most useful, and that the student teachers received a wide range of feedback which gave them clear focus and direction for their practice. Thus, both types of feedback are important for the student teachers; however, the written one could be more effective as it would enable them to keep these written comments, reflect and refer to them when needed.

\section{THE EFL TEACHING PRACTICUM}

The English department of a faculty of education, PU in Yemen offers a B Ed programme. It is a four-year programme to educate English language teachers for local primary and secondary schools. The programme offers 142 credit hours and focuses on the subject matter of teaching English. It offers intensive courses on teaching methods, language skills, English literature, along with numerous courses in general pedagogical knowledge and teaching practice. In the seventh semester, students join local public schools for practicum. The student teachers start teaching for one semester (twelve weeks) for about 5 to 8 periods per week with 35 minutes per each. They are given enough time to get used to the teaching setting before being supervised. During practicum they are supervised by four different supervisors: the mentors (called cooperating teacher in this study), the school headmaster and two university supervisors. These supervisors should conduct minimally two supervisory observations to observe, assist and assess each student teacher's teaching. Each lesson observation is usually followed by a short feedback session in which the supervisor provides suggestions and comments for improvement based on the lesson observed and the written lesson plan.

Previous studies reported that Yemeni EFL student teachers experienced several challenges and difficulties among which is the insufficient support caused by the absence of supervisors (Al-Majeedi, 2003). Although they are guided, observed and evaluated by a panel of supervisors consisting of the cooperative teacher, the university supervisors and the school headmaster, they complained of getting insufficient supervisory support. They claim that they lack opportunities to contact and negotiate ideas with supervisors because of their eventful schedules (Al-Jaro \& Asmawi, 2019). Therefore, the interest of this study arises from the need to fill the gap in the literature by investigating supervisor roles during practicum and exploring barriers to effective supervision. Findings might contribute to better understanding for necessary changes in the teacher education program policy and practice in Yemen. The following questions guided this study:

1. How does the supervisory support assist the EFL student teachers to practice teaching during practicum?

2. What are the barriers of effective supervision during teaching practicum?

\section{METHODOLOGY}

\subsection{Research Design}

This study adopted a qualitative research design using a multiple case study approach. The case study design was used to provide an in-depth description supervisory support received by a group of EFL student teachers during teaching practicum. A case study is beneficial especially in the first stages as it presents a thorough description of the experience of the participants to identify categories and themes to describe the case and introduce contemporary issues for future studies (Gravetter \& Forzano, 2018). Therefore, a qualitative 
case study design is suitable to be employed in this study because it comes up with a rich description and explanation of the EFL supervisory support during teaching practicum.

\subsection{The Context of the Study}

The study was conducted at a Faculty of Education, a Public University (PU) as well as four different public secondary schools in four cities in Yemen. The fourth-year student teachers were selected from public schools where they practise teaching for a complete semester. Every student teacher was guided and assessed by four supervisors, namely, the cooperating teacher, the school headmaster/headmistress, the university academic supervisor and the university educational supervisor. The supervisors were expected to observe the student teachers and give feedback on their teaching performance in the first observation and evaluate their teaching practice in the second/last observation based on evaluation forms developed by the teaching practicum office at the faculty.

\subsection{The Participants}

The participants of the study were selected through purposeful sampling because it is useful for intentionally selecting the individuals and sites and understanding the phenomenon being investigated in the current study (Creswell, 2012). For the purpose of this study, four student teachers as multiple cases were selected to participate in this study which is a preferred method over a single participant as a case (Yin, 2009). Additionally, it was not sensible to choose more cases because the researcher might need longer time to spend on exploring the depths of each individual case (Creswell, 2012). Therefore, multiple case study would enable the researcher to analyse the data within each site and across different sites (Yin, 2009) and understand the similarities and differences between cases. Eventually, the researchers can provide the literature with important influences from these differences and similarities to contribute to a better understanding of the phenomenon under investigation. Four student teachers and their supervisors were the selected participants in the study. They were given the following pseudonyms: Nada, Hassan, Mona and Saied. They are of similar ages $(25,22,23,22$ years respectively). Every student teacher was guided by four supervisors. Two of them were university supervisors: the university academic supervisor who was a lecturer at the department of English language at the faculty of education, and the university educational supervisor who was a lecturer at the department of educational and psychological sciences at the faculty of education. The other two supervisors were school supervisors: the cooperating teacher and the school headmaster.

The study participants were briefed on the objectives and procedures of the study. Furthermore, they were informed that their participation depended on their willingness, and they were free to answer, decline any of the researcher questions or withdraw from the study at any time. They showed their agreement to participate in the study and signed on the informed consent forms.

\subsection{Data Collection}

The four selected student teachers and their supervisors were interviewed. Interviews in the context of this study provided a full description of the student teachers' teaching practices during practicum and deeply emphasized the role of their supervisors in enhancing their pedagogical practices. Semi-structured 'one-on-one interviews' (Creswell, 2012) were developed by the researcher to further understand the Yemeni EFL supervisory support during practicum. Semi-structured interviews were most suitable for collecting data for the 
study to probe more deeply issues of interest to the interviewees through follow up questions. Also, through them, the interviewees were allowed to express their thoughts freely from their own perspectives without any hindrance or interruption.

For the purpose of collecting data, the researchers developed four semi-structured, 'interview protocols' (Creswell, 2012) for four different types of participants: the student teachers, the cooperating teachers, the school headmasters and the university supervisors. These protocols aided as a guide to assure that all intended areas were covered. It was part of the researchers' plan to give the supervisors enough time to observe their supervisees' teaching practice at school, and to best capture and realize their experience in supervision. Therefore, the researchers intend to understand the experience of those supervisors in guiding the student teachers and enhancing their pedagogical practice during practicum. They prepared some guided questions with sub-questions to elicit more information about the supervisory support to assist the student teachers during their teaching practices, the challenges that they faced during supervision and their suggestions to further improve teaching practice.

All interviews were conducted in English, except the interviews with the school headmasters/headmistress and the educational university supervisors. They were carried out in Arabic language because they are unable to express their thoughts clearly in English. Therefore, the researchers translated these interview protocols into Arabic. The first researcher recorded all interviews using his mobile recorder and took notes during the interviews which ranged in length between 20-30 minutes per each. The interviews were then transcribed verbatim and immediately by the researchers who listened to the audio-recording many times and added the taken notes to the manual transcription. The interviews with the school headmasters and the academic university supervisors were first transcribed verbatim in Arabic by listening to the audio-recording many times and adding the taken notes to the transcription. Then the Arabic transcripts were literally translated into English. All the recorded interviews with the transcripts were stored in a special memory disk to be easily retrieved. To check the accuracy and reliability of the translation, both the Arabic and English transcripts were emailed to a professional translator who provided the researchers with effective feedback. The researchers then made the necessary changes to the final drafts of the transcripts.

\subsection{Data Analysis}

The four selected student teachers and their supervisors were interviewed. Interviews in the context of this study provided a full description of the student teachers' teaching practices during practicum and deeply emphasized the role of their supervisors in enhancing their pedagogical practices. Semi-structured 'one-on-one interviews' (Creswell, 2012) were developed by the researcher to further understand the Yemeni EFL supervisory support during practicum. Semi-structured interviews were most suitable for collecting data for the study to probe more deeply issues of interest to the interviewees through follow up questions. Also, through them, the interviewees were allowed to express their thoughts freely from their own perspectives without any hindrance or interruption.

For the purpose of collecting data, the researchers developed four semi-structured, 'interview protocols' (Creswell, 2012) for four different types of participants: the student teachers, the cooperating teachers, the school headmasters and the university supervisors. These protocols aided as a guide to assure that all intended areas were covered. It was part of the researchers' plan to give the supervisors enough time to observe their supervisees' teaching practice at school, and to best capture and realize their experience in supervision. Therefore, the researchers intend to understand the experience of those supervisors in guiding 
the student teachers and enhancing their pedagogical practice during practicum. They prepared some guided questions with sub-questions to elicit more information about the supervisory support to assist the student teachers during their teaching practices, the challenges that they faced during supervision and their suggestions to further improve teaching practice.

All interviews were conducted in English, except the interviews with the school headmasters/headmistress and the educational university supervisors. They were carried out in Arabic language because they are unable to express their thoughts clearly in English. Therefore, the researchers translated these interview protocols into Arabic. The first researcher recorded all interviews using his mobile recorder and took notes during the interviews which ranged in length between 20-30 minutes per each. The interviews were then transcribed verbatim and immediately by the researchers who listened to the audio-recording many times and added the taken notes to the manual transcription. The interviews with the school headmasters and the academic university supervisors were first transcribed verbatim in Arabic by listening to the audio-recording many times and adding the taken notes to the transcription. Then the Arabic transcripts were literally translated into English. All the recorded interviews with the transcripts were stored in a special memory disk to be easily retrieved. To check the accuracy and reliability of the translation, both the Arabic and English transcripts were emailed to a professional translator who provided the researchers with effective feedback. The researchers then made the necessary changes to the final drafts of the transcripts.

\section{FINDINGS}

The result of the cross-case analysis identified four emerging themes; a) supervisory support on lesson planning, b) supervisory support on teaching strategies, c) supervisory support on classroom management, and d) number of observations. Firstly, the findings revealed that the received supervisory support influenced the student teachers' pedagogical practices in terms of their lesson planning. All the student teachers received insufficient support and guidance from their four supervisors. For example, Hassan received some guidance only from the cooperating teacher who provided him with some comments and instructions to better refine his plans. Also, Mona was only guided by her academic university supervisor, and there was a clear lack of support from other supervisors. Additionally, Saeed received some comments on his lesson plans only from the cooperating teacher and the educational university supervisor. On the other hand, Nada received considerable support and effective feedback on her plans. She benefited a lot from the comments she received from her cooperating teacher. However, there were no noteworthy and constructive comments on her plans that she received from her university supervisors. Table 1 shows an annotated matrix for this theme. It includes some representative excerpts for the emerging subthemes.

\section{Table 1. Annotated Matrix of Theme 1- Received Supervisory Support on Lesson Planning}

\begin{tabular}{ll}
\hline Theme 1: & Supervisory Support on Lesson Planning \\
\hline Cases & Excerpts \\
\hline Nada & "Concerning the lesson plan, I have commented on the one that I have observed. Two comments \\
& were given. The first was about timing the sections of the lesson plan. ... The second comment \\
& was on the plan evaluation section." (The cooperating teacher). \\
& "She has got a very good lesson plan and she seems to have prepared that quite well. I only \\
& observed some small spelling mistakes in the steps that she wrote" (the academic university \\
& supervisor).
\end{tabular}




\begin{tabular}{|c|c|}
\hline & $\begin{array}{l}\text { "Really, I didn't get any benefit from the academic university supervisor, but I have received some } \\
\text { support from the cooperative teacher the school headmistress" (Nada). }\end{array}$ \\
\hline Hassan & $\begin{array}{l}\text { "The student teacher [Hassan] showed me his lesson plan before every class he is going to teach, } \\
\text { and I give him some comments and instructions to make his teaching class more interesting. As I } \\
\text { have a long experience in teaching, I provide the student teacher with some tips even they are not } \\
\text { recorded in his lesson plan as some lessons based on what students have studied in a previous } \\
\text { year". (the cooperating teacher). } \\
\text { "I did not receive any support from my supervisors in lesson planning except my cooperating } \\
\text { teacher who usually gives me some general tips on planning". (Hassan). } \\
\text { "As I said before, checking the lesson plan is not related to us. We have received an evaluation } \\
\text { form to assess the student teacher's performance against a set of criteria, and the lesson plan is not } \\
\text { in the form. But I have told him [Hassan] to be careful of timing the lesson plan" (the academic } \\
\text { university supervisor). } \\
\text { "I have seen the lesson plan and it was a copy from the guidebook or the teacher's book. I asked } \\
\text { the student teacher to rewrite the objectives of the lesson and to be careful about the time. He was } \\
\text { also asked to make his plan more practical and to divide the time of the steps he has in order to } \\
\text { achieve the objectives of the lesson" (the academic university supervisor). } \\
\text { "The student teacher only writes some guidelines for his lesson plan which is not good for a } \\
\text { beginning teacher. I advised him to write a detailed lesson plan as he is in a training stage and he } \\
\text { should write everything as he is subjected to evaluation" (the academic university supervisor). }\end{array}$ \\
\hline Mona & $\begin{array}{l}\text { "In fact, I haven't received sufficient comments on my lesson plan from any one of my } \\
\text { supervisors, except my university supervisor (Academic). She advised me to write my lesson plan } \\
\text { in a table" (Mona). } \\
\text { "Before the class, I had sat with her and I had looked at her lesson plan. I looked at the goals that } \\
\text { she is trying to achieve. After the class, I asked her how she made sure that the goals were } \\
\text { achieved" (the academic university supervisor). } \\
\text { "Mona has a problem in stating the objectives and she wrote a very short lesson plan. So, I advised } \\
\text { her to consider these in her next planning" (the academic university supervisor) } \\
\text { "I provided her with some models for lesson plan to know how to plan her lesson before teaching. } \\
\text { Also, to give her the teacher guidebook in order to plan her lesson in a very good style" (the } \\
\text { cooperating teacher). }\end{array}$ \\
\hline Saeed & $\begin{array}{l}\text { I show my lesson plans to my supervisors, and there were very glad. They didn't comment on my } \\
\text { lesson except with the procedures section. They suggested writing detailed steps in the procedures } \\
\text { section" (Seed) } \\
\text { "I advised the student teacher [Saeed] to include a group of essential elements and secondary } \\
\text { elements in his lesson plan according to the subject. The first essential element is the lesson } \\
\text { objectives which most of the student teachers are weak in stating these objectives. Also, I advised } \\
\text { the student teacher [Saeed] to write a detailed lesson plan to refer to it during the presentation of } \\
\text { the lesson, and he can present his lesson well according to what is planned. Furthermore, I guided } \\
\text { him to include timing to all the plan elements and practice before a teaching class" (the } \\
\text { educational university supervisor) }\end{array}$ \\
\hline
\end{tabular}

Secondly, the findings indicate that the received supervisory support influenced the participants' pedagogical practices in terms of teaching strategies. All the participants received guidance from their supervisors based on their teaching practices. On the other hand, Nada, Hassan and Saeed appreciated the support they received from their cooperating teachers on teaching strategies. Only Mona was not sufficiently guided by her cooperating teacher on selecting appropriate teaching methods and approaches. Perhaps, this is due to the limited interaction between her and the cooperating teacher as the latter was very busy with the school administration. Likewise, Nada, Hassan and Saeed participated student teachers received extensive comments on their teaching strategies from their academic university supervisors. Only Mona was not satisfied with the comments she received from her academic university supervisor. She thought that the strategies he recommended were not applicable to the teaching context. Additionally, only Nada received considerable feedback from her school headmaster on her teaching strategies. However, Hassan, Mona and Saeed did not record any support from the school headmasters. They claimed that they were not experts in 
English language teaching. Similarly, all the student-teacher participants declared no support from the educational university supervisors on teaching strategies for the same reason mentioned above. Table 2 shows an annotated matrix for this theme. It includes some representative excerpts for the emerging subthemes.

\section{Table 2. Annotated Matrix of Theme 2- Received Supervisory Support on Teaching Strategies}

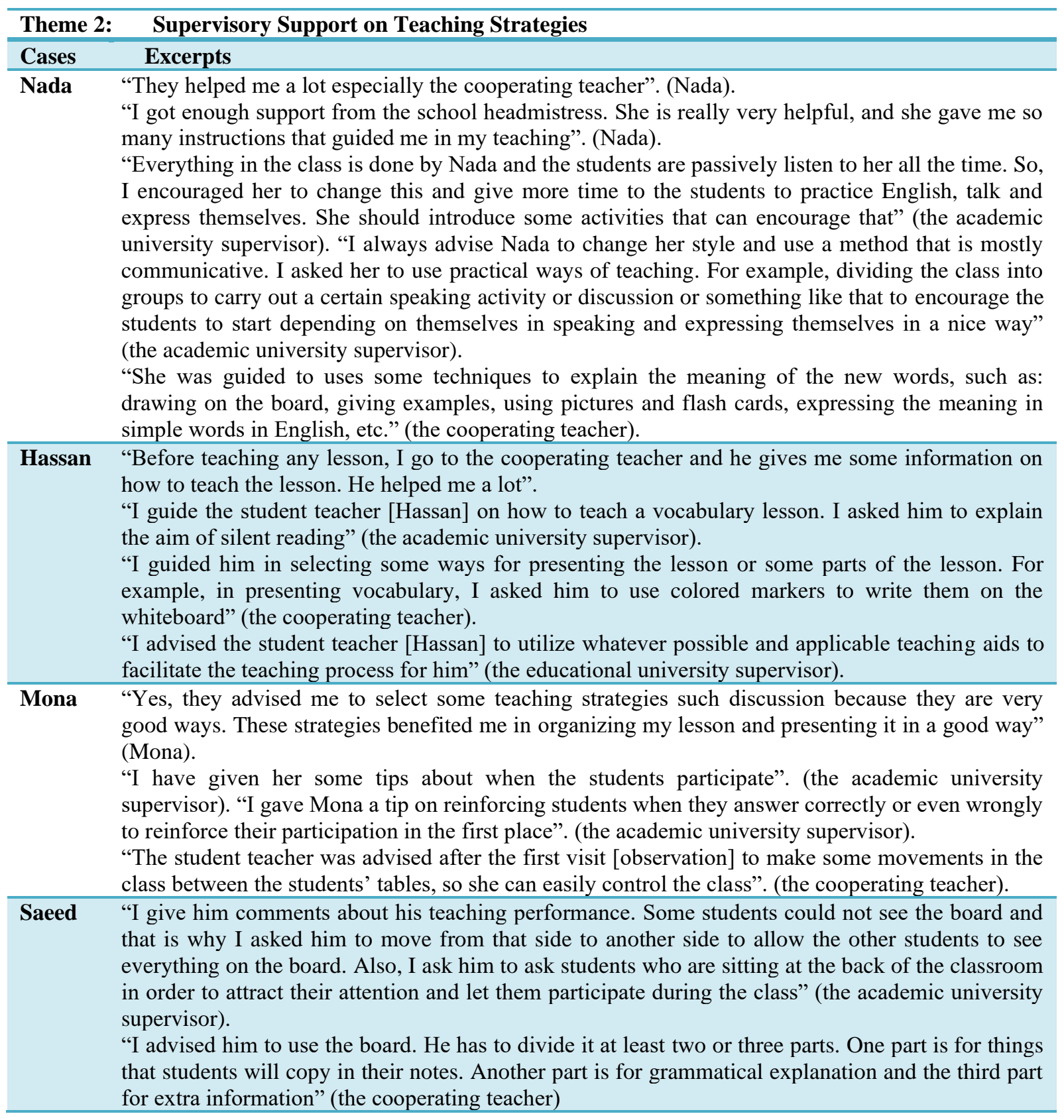

Thirdly, the findings showed that the received supervisory support assisted the student teacher participants' pedagogical practices in terms of classroom management. All the participants received considerable guidance from their cooperating teachers and appreciated their roles in giving effective comments on their classroom management practices. Also, Nada, Mona and Saeed were provided with some classroom management tips from their educational university supervisors based on their classroom observations. However, Hassan's 
educational university supervisor had no effort to guide Hassan on the way he managed the class. This was because of the limited interaction between him and his supervisee which was due to the limited observations he did.

On the other hand, Nada emphasized the benefits of comments provided by the school headmaster. However, the other three student teachers declared limited supervisory support from the school headmasters. Perhaps, it was due to the limited classroom observations they had and the lack of interaction with their supervisees. As for Saeed's case, the school headmaster was not an expert in English language teaching, and he directed the general supervision to the cooperating teacher who followed Saeed's progress. Likewise, Hassan and Mona were provided with some instructions from their academic university supervisors. These instructions were beneficial to deal with students and control their classes. However, Nada felt that her academic university supervisor's comments were mainly related to her grammatical mistakes and not related to classroom management. As for Saeed, his academic university supervisor appreciated Saeed's way of controlling the class. Therefore, he had no effective comments on Saeed's classroom management. Table 3 shows an annotated matrix for this theme. It includes some representative excerpts for the emerging subthemes.

\section{Table 3. Annotated Matrix of Theme 3- Received Supervisory Support on Classroom Management}

\begin{tabular}{|c|c|}
\hline Theme 3: & Supervisory Support on Classroom Management \\
\hline Cases & Excerpts \\
\hline Nada & $\begin{array}{l}\text { "I have advised her to divide the class into groups which might help her to better control the class } \\
\text { and ensure that all the students can participate at the same time" (the cooperating teacher). } \\
\text { "One of her [the school headmistress] comments, I remember well, she asked me to make the } \\
\text { students busy all the time in order to control the class and don't force any student to participate. } \\
\text { She guided me to deal with students as sisters, not as students" (Nada). }\end{array}$ \\
\hline Hassan & $\begin{array}{l}\text { "I usually advise my supervisee [Hassan] to follow some strategies in order to control the class } \\
\text { well. First, to make the learners busy all the time with class activities. Second, to avoid presenting } \\
\text { his lesson quickly, keeping silent after that and asking the learners to do so. Third, to involve the } \\
\text { learners in attractive class activities. Fourth, to vary the way of teaching and change the mood of } \\
\text { the class" (the cooperating teacher). } \\
\text { "I gave him some instructions in managing the class. For example, I told him 'while writing on } \\
\text { the board, make you writing clear to all the students to read and write, ask some students to read } \\
\text { loudly in order to attract other students' attention" (the academic university supervisor). }\end{array}$ \\
\hline Mona & $\begin{array}{l}\text { "I told her a lot of information about how to deal with the students inside the class in order to } \\
\text { prepare well before teaching" (the cooperating teacher). } \\
\text { "Another thing was her movement inside the classroom. She was moving to one side and not to } \\
\text { the other. I told her to make the students feel that she is present most of the time here and there. } \\
\text { Also, it is important for class management (the academic university supervisor). } \\
\text { "I gave the student teacher [Mona] some common comments based on her teaching practice: the } \\
\text { first one is the classroom management which very important to present her lesson well. To control } \\
\text { the class, she should prepare the lesson well. Also, I provided her with some instructions to } \\
\text { increase her self-confidence, deal with learners' behaviours and monitor their learning" (the } \\
\text { school headmaster). }\end{array}$ \\
\hline Saeed & $\begin{array}{l}\text { "Most of the received instructions from my cooperating supervisor were related to the way I deal } \\
\text { with students. He usually provided me with some examples of problematic situations he faced } \\
\text { during his teaching experience and the recommend solutions for these problems" (Saeed). }\end{array}$ \\
\hline
\end{tabular}

Fourthly, the findings indicated that the received supervisory support was affected by the number of observations and the consequent feedback after each observation. Although two supervisors' observations were the minimum number that each supervisor should carry out during practicum, some student-teacher participants were only observed once. That was because of some restrictions such as the workloads of supervisors, a big number of 
supervisees and the remote areas of the host schools. The following table, Table 4 shows the number of observations conducted for each student teacher:

Table 4. Number of Observations

\begin{tabular}{lcccc}
\hline Student & \multicolumn{4}{c}{ Number of observations } \\
\cline { 2 - 5 } Teacher & $\begin{array}{c}\text { Cooperating } \\
\text { Teacher }\end{array}$ & $\begin{array}{c}\text { School } \\
\text { headmaster }\end{array}$ & $\begin{array}{c}\text { Academic } \\
\text { University } \\
\text { Supervisor }\end{array}$ & $\begin{array}{c}\text { Educational } \\
\text { University } \\
\text { Supervisor }\end{array}$ \\
\hline Nada & 2 & 2 & 1 & 1 \\
\hline Hassan & 2 & 1 & 2 & 1 \\
\hline Mona & 2 & 2 & 2 & 3 \\
\hline Saeed & 2 & 2 & 1 & 1 \\
\hline
\end{tabular}

Although all the student teacher participants were observed twice by their cooperating teachers, they felt that two observations were not enough to provide them with needed feedback on their teaching practices. The cooperating teachers, in their turn, asserted that the limited support was due to their workloads in teaching and supervising other student teachers in their schools. On the other hand, three school headmasters observed their supervisees only twice during practicum. However, Hassan's school headmaster observed him only once. He admitted that to some restrictions such as his school responsibilities and the big number of student teachers that he was supervising. Similarly, only two academic university supervisors observed and guided their student teachers twice during teaching practice at schools. They thought that more observations and consequent feedback sessions would contribute to better teaching practice for their supervisees. Whereas, the other two academic university supervisors, Nada and Saeed's academic university supervisors were only able to observe once. They imputed that to the short period of practicum at schools. Likewise, three out of four educational university supervisors observed their supervisees, Nada, Hassan and Saeed only once during practicum. They declared that the heavy working hours at the university, the lack of the teaching staff at the educational department and the big number of the student teachers were challenges for supervisors that hindered them to observe their supervisees for more than once and provided necessary support. Whereas, Mona's educational university supervisor was the only supervisor who managed to observe her three times. However, his observations were not carried for three completed classes. Table 5 shows an annotated matrix for this theme. It includes some representative excerpts for the emerging subthemes.

\section{Table 5. Annotated Matrix of Theme 4- Received Supervisory Support (Number of Observation)}

\begin{tabular}{cl}
\hline Theme 4: & Number of observations \\
\hline Cases & \multicolumn{1}{c}{ Excerpts } \\
\hline Nada & "I have a class at the same time of Nada's class, so I couldn't attend more than two classes, \\
& $\begin{array}{l}\text { and this is a minimum number of observations" (the cooperating teacher). } \\
\text { "If I have a chance to visit her for the second time, that would be much better. At least to see } \\
\text { what extent she has practically applied what I asked her to do on the first visit" (the academic } \\
\text { university supervisor). }\end{array}$ \\
& $\begin{array}{l}\text { "... when I observe him for more than twice or three times, I think it will be enough to } \\
\text { evaluate his teaching practice" (the cooperating teacher). } \\
\text { "I think they [two observations] are not enough because I can't evaluate the student teacher in } \\
\text { one or two visits. I need to observe the student teacher teaching performance more times in } \\
\text { order to evaluate different things" (the academic university supervisor). }\end{array}$ \\
\hline
\end{tabular}




"Al-Kefah Secondary School (pseudonym) is a very big school and every year many student
teachers with different fields join the school to do their teaching practicum. It is to some
extent hard for the school headmaster to observe all those student teachers" (the school
headmaster).
"One of the big challenges that we face is the big number of student teachers we observe and
supervise. ... I tried to visit the student teacher once and gave him some comments to be
followed" (the educational university supervisor).
"One challenge for me was my heavy working load and my position as a deputy school
manager which hindered me to observe the student teacher more than twice and gave her
more time for meeting and discussion" (the cooperating teacher).
"So, if she gets more supervision sessions, she will get improved more"
"One of the challenges was the distance between college and schools since I have to visit four
different schools in four different areas, so managing the time was difficult sometimes.
Sometimes, I went to schools and came back to the college in the same day. It was difficult,
but I managed" (the academic university supervisor).
"Sometimes, there are factors that may affect the number of observations such as the
difficulty to reach remote areas where some student teachers are practicing teaching" (the
educational university supervisor)
"I faced some challenges during my supervision, for example, sometimes I want to observe
the student teacher, but I have a class at the same time. Some other times, I prepared for the
observation, then something else appears and I couldn't attend with the student teacher as I
am busy with the school administration. However, I tried to overcome these challenges, and I
managed to observe his teaching performance twice" (the cooperating teacher).
"It is supposed to observe the student teacher more than once, but unfortunately we have not
enough teaching staff to observe them more than one observation. Also, some of the student
teachers are teaching in remote areas, so it is hard to visit the student teacher twice. (the
educational university supervisor).

The overall supervisory support received by the Yemeni EFL student teachers was insufficient and not up to the level to develop their teaching practice during practicum. Therefore, they tried other ways such as consulting other experts and friends, reading up some available references, or reverting to what they themselves were taught, as in the case of Saeed. In this regard, the researcher thinks that the supervisors' roles in the Yemeni EFL context during practicum are not appropriately implemented which urgently need reconsideration from the teacher education program administrators in Yemen. Another important issue is the multiple supervision which appeared to be quantity-focused rather than quality-focused. Hence, the researchers suggest that solo supervision with a capable expert would be better for the Yemeni EFL student teachers' professional practice as it would, as the researchers think, solve many of the drawbacks of multiple supervision.

Therefore, the findings reveal two main conclusions. First, the limited supervisory support affects the student teachers' pedagogical practices which was due to the limited number of visits and classroom observations and fewer opportunities for interaction between student teachers and their supervisors. Most of the supervisors had visited and observed their supervisees only once which was not enough for them to provide necessary support and feedback. Additionally, the student teachers did not get the instant support needed from their supervisors. This conclusion is based on the findings that the student teacher participants received insufficient support and guidance from panel of supervisors in terms of lesson planning, teaching strategies and classroom management. Second, there is a lack of support and guidance from part of the school headmasters and the educational university supervisors. This conclusion is drawn based on the findings that most of them had no effective support and feedback on the student teachers' pedagogical practices especially teaching strategies. 


\section{CONCLUSION AND DISCUSSION}

This study reveals two conclusions related to received supervisory support during the EFL teaching practicum in Yemen. The first conclusion discusses the influence of the limited supervisory support on the student teachers' pedagogical practices. The second conclusion presents the barriers that limit the supervisory support. The findings of this study concluded that there is limited support and guidance from the panel supervisors. In the study, the four student-teacher participants received irregular and detached support and guidance on their pedagogical practices. At the same time, there were some disagreements with the comments of supervisors. Furthermore, there were limited numbers of supervisory visits to observe and provide student-teacher participants with feedback on their teaching practices. Most of the supervisors, especially the university supervisors and the school headmaster visited their supervisees only once during the whole duration of teaching practice at schools which was not satisfactory for the student teachers to receive necessary feedback on their practices. Besides, there were fewer opportunities for the student-teacher participants to interact with their supervisors. That was because of their full engagement of teaching and study. They had full-time teaching for four days at schools and had to go to the university to study and attend classes for one day.

These findings are aligned with a number of previous studies (e. g., Ali, et al, 2014; Cahn, 2014; Chien, 2013; Koerner et al, 2002) that limited interaction influences the student teachers' teaching experience, leads to limited engagement of teaching style and hinders a deep learning to take place. Thus, one significant way to enhance the student teachers' pedagogical practices is to provide them with supervisory productive learning conversations through which they can develop their teaching experience.

Additionally, in the emerging findings of the present study, a presence of some barriers seemed to influence the supervisory support. First, the university supervisors and school headmasters had no obvious effect on the student teachers' classroom practices. In comparison with cooperating teachers, one classroom observation and post-observation feedback for twelve weeks (i.e., practicum duration at schools) do not constitute adequate supervision and guidance. There were some restrictions that seemed to limit their supervision including, a large number of supervisees, shortage of teaching staff, heavy working hours at the university, and the difficulty to reach host schools in remote areas.

Second, there was a lack of supervision from the part of the educational university supervisors and the school headmasters. Most of the student-teacher participants in the study expressed their dissatisfaction with the supervision and support they have received from the school headmasters and the educational university supervisors, especially with pedagogical issues. In turn, those supervisors admitted that the lack of supervision and imputed it to the limited time as they are occupied with the school administration (as in the case of school headmaster) and/or to their lack of knowledge in teaching English language.

Third, despite the limited supervisory support received by the student-teacher participants, there were ambiguous and overlapped roles of the university supervisors and cooperating teachers. According to (Hennissen et at, 2008), the university supervisors and cooperating teachers should assist the student teachers to learn from teaching practices. They have distinct roles based on a variety of their experience and expertise. For instance, the cooperating teacher should contribute to the student teachers' learning at the level of direct and indirect practices and focus mainly on craft knowledge. However, the university supervisors can contribute to the level of practical principles and disciplinary theory and focus on the principle-oriented outcomes (Dunne \& Bennett; Furlong, Hirst, Pocklington, \& Miles as cited in Svojanovsky, 2017). Therefore, both should participate in mentoring student 
teachers through carrying out supervisory activities that could help their supervisees learn from teaching practice (Hennissen et al., 2008).

More significantly, this study revealed an important element that has not been discussed in the literature. Multiple supervision for the same student teacher (i.e., academic and educational university supervisors, cooperating teachers and school headmaster), who had different qualifications and expertise, had its significant influence on the student-teacher participants' teaching practice. The supervisors' variant opinions and suggestions caused confusion among the student-teacher participants. Therefore, the student teachers were disoriented and bewildered about whom they should follow. In addition, there was no clear and definite vision of the supervisors' roles as all of them observe the same student teacher to investigate and assess similar pedagogical issues. A question might be asked about benefit of multiple supervision. Hence, EFL teacher education program should assign experienced supervisors to guide the student teachers and enhance their learning capacity to teach during teaching practice.

In the context of this study, the supervisory support was underpinned by the sociocultural theory of learning (Vygotsky, 1978; 1986) specifically the concepts of ZPD and its implications for scaffolding and mediation. With reference to the findings of the study, the student teachers encountered some challenges during their pedagogical practices which entailed social assistance from their supervisors. According to the theory, such social assistance should be maximized to solve student teachers' teaching problems and promote their pedagogical knowledge and ability to teach. However, the findings revealed some limitations in the supervisory support and guidance which limited the student teachers' pedagogical practices and their potential level of development. Therefore, these findings are indirectly supported by the socio-cultural theory of learning in the case that the lack of social interaction with experts would hinder the accomplishment of the potential level of development. On the other hand, the challenges and barriers to effective supervisory support would probably lead to confusing the student teachers' pedagogical practices, and subsequently, influence their professional teaching practice. As a result of all these, EFL effective supervisory support during practicum must be taken into account and further developed to ensure accomplishing better levels of EFL student teachers' pedagogical practices.

The study reveals the importance of the supervisory support to lead to successful teaching practice. It suggests some important practical implications for EFL teacher education program in Yemen. As the findings of the present study showed limited supervisory support received by the student-teacher participants; there is a pressing need to put more emphasis on developing the supervisory skills among the practicum supervisors. This is because the availability of effective guidance and support is an essential condition for student teachers to learn and benefit from teaching practice in schools. As such, a great demand is placed on the professionalism of supervisors to encourage and support student teachers to learn from their practical experiences (Hennissen et al., 2008). They should be assigned in practicum based on their areas of expertise instead of their availability. The findings of the study revealed limited interaction, a limited number of supervisory observations which led to fewer opportunities for student-teacher participants to interact with supervisors.

Added to that, a number of barriers were underscored and reported to cause insufficient supervision and support. Hence, it is essential for EFL teacher education program administrators and developers to reconsider the supervision plan in order to identify the roles of each supervisor, increase the minimum number of observations and provide alternative means of interactions and collaboration. These must be well-defined in advance. Otherwise, the desired effect of practicum supervision might not occur. Additionally, they are requested 
to re-investigate the barriers of effective supervision and seek to find immediate remedies to these.

\section{REFERENCES}

Ali, H. I. H., \& Al-Adawi, H. A. (2013). Providing effective feedback to EFL student teachers. Higher Education Studies, 3(3), 21-35.

Ali, M., Othman, A., \& Karim, A. (2014). Issues and concerns faced by undergraduate language student teachers during teaching practicum experiences. The Malaysian Online Journal of Educational Management, 2(3), 22-30.

Al-Jaro, M. S., \& Asmawi, A. (2019). An EFL teacher education programme: Issues and concerns from a Yemeni university. Arab World English Journal, 10(1), 139 -154.

Aimin, L. (2013). The Study of second language acquisition under cocio-cultural theory. American Journal of Educational Research, 1(5), 162-167.

Al-Majeedi, A. (2003). Evaluating the program of practicum in the education faculties in Hadhramout university. A Quarterly Research Refereed Journal. A Series of Human Arts and Sciences: Taiz University, 5, 95-134.

Al-Sohbani, Y. (2013). An Exploration of English language teaching pedagogy in secondary Yemeni education: A case study. International Journal of English Language \& Translation Studies, 1(3), 40-55.

Babkie, M. (1998). Work successfully with a student teacher. Intervention in School and Clinic, 34(2), 115-117.

Bain, J., Mills, C., Ballantyne, R., \& Packer, J. (2002). Developing reflection on practice through journal writing: Impacts of variations in the focus and level of feedback. Teachers and Teaching, 8(2), 171-196.

Behroozizad, S., Nambiar, R., \& Amir, Z. (2014). Sociocultural theory as an approach to aid EFL learners. The Reading Matrix, 14(2008), 217-226.

Black, P., \& Wiliam, D. (1998). Inside the black box: Raising standards through classroom assessment. London: Kings College School of Education

Braun, V. \& Clarke, V. (2006). Using thematic analysis in psychology. Qualitative Research in Psychology, 3(2), 77-101.

Canh, L. Van. (2014). Great expectations: The TESOL practicum as a professional learning experience. TESOL Journal, 5(2), 199-224.

Chien, C.W. (2013). Teaching in a summer school program as practicum: Challenges and implications. Journal of Language Teaching and Research, 4(5), 1011-1017.

Clarke, A., Triggs, V., \& Nielsen, W. (2013). Cooperating teacher participation in teacher education: A review of the literature. Review of Educational Research, 84(2), 163202.

Copland, F. (2010). Causes of tension in post-observation feedback in pre-service teacher training: An alternative view. Teaching and Teacher Education, 26(3), 466-472.

Copland, F. (2011). Negotiating face in feedback conferences: A linguistic ethnographic analysis. Journal of Pragmatics, 43, 1-18.

Crasborn, F., Hennissen, P., Brouwer, N., Korthagen, F., \& Bergen, T. (2008). Promoting versatility in mentor teachers' use of supervisory skills. Teaching and Teacher Education, 24(3), 499-514.

Creswell, J. W. (2012). Educational Research: planning, conducting, and evaluating quantitative and qualitative research (4th ed.). Upper Saddle River, NJ: Pearson Education, Inc. 
Darling-Hammond, L. (2000). How Teacher education matters. Journal of Teacher Education, 51(3), 166-173.

Darling-Hammond, L., \& J. Baratz-Snowden. (2005). A good teacher in every classroom: Preparing the highly qualified teachers our children deserve. San Francisco, CA: John Wiley \& Sons.

Duquette, C. (1994). The role of the cooperating teacher in a school-based teacher education program: Benefits and concerns. Teaching and Teacher Education, 10(3), 345-353.

Ellis, R., (2000). Task-based research and language pedagogy. Language Teaching Research, 4(3), 193-220

Endeley, M. N. (2014). Teaching practice in Cameroon: The effectiveness of the University of Buea model and implications for quality. Australian Journal of Teacher Education, 39(11), 147-160.

Faculty of Education Guide. (2012). Faculty of Education, PU, Yemen.

Fahim, M., \& Haghani, M. (2012). Sociocultural Perspectives on Foreign Language Learning. Journal of Language Teaching and Research, 3(4), 693-699.

Farrell, T. S. C. (2007). Failing the Practicum : Narrowing the gap reflective practice. TESOL Quarterly, 41(1), 193-201.

Farrell, T. S. C. (2008). 'Here's the book, go teach the class': ELT practicum support. RELC Journal, 39(2), 226-241.

Friese, S. (2012). ATLAS.ti 7 User Manual. Berlin, Germany: ATLAS.ti Scientific Software Development GmbH.

Gheisari, N., \& Jamali, F. (2014). Sociocultural theory in second language acquisition: Tenets and pedagogical implications in an EFL setting. Global Journal of Foreign Language Teaching, 04(2), 72-80.

Graham, M. (1996). Guiding tomorrow's teachers. Learning, 26(5), 37-38.

Graham, B. (2006). Conditions for successful field experiences: Perceptions of cooperating teachers. Teaching and Teacher Education, 22(8), 1118-1129.

Gravetter, F. J., \& Forzano, L. A. B. (2018). Research methods for the behavioral sciences. Cengage Learning. Boston, USA.

Haciomeroglu, G. (2013). The field experiences of student teachers and effective Mathematics teaching in Turkey. Australian Journal of Teacher Education, 38(2), 132-142.

Hammond, J. (Ed.) (2002) Scaffolding Teaching and Learning in Language and Literacy Education. Newtown, Australia: PETA

Hyland, F., \& Lo, M. (2006). Examining interaction in the teaching practicum: issues of language, power and control. Mentoring \& Tutoring: Partnership in Learning, 14(2), 163-186.

Ibrahim, A. (2013). Approaches to supervision of student teachers in one UAE teacher education program. Teaching and Teacher Education, 34(2013), 38-45.

Johnson, K. E. (2006). Teacher Education. TESOL Quarterly, 40(1), 235-257.

Koerner, M., Rust, F., \& Baumgartner, F. (2002). Exploring roles in student teaching placements. Teacher Education Quarterly, 29(2), 35-58.

Kourieos, S. (2012). The impact of mentoring on primary language teacher development during the practicum. ELTED, 15(2012), 57-64.

Lu, H. (2013). Pre-service teachers' issues in the relationship with cooperating teachers and their resolutions. Us-China Education Review, 3(1), 18-28.

Merç, A. (2015). Assessing the performance in EFL teaching practicum: Student teachers' views. International Journal of Higher Education, 4(2), 44-56.

Miles, M. B., Huberman, A. M., \& Saldana, J. (2014). Qualitative Data Analysis: A Methods Sourcebook ( $3^{\text {rd }}$ ed.). Thousand Oaks, CA: Sage Publications. 
Moody, J. (2009). Key elements in a positive practicum: insights from Australian postprimary pre-service teachers. Irish Educational Studies, 28(2), 155-175.

Mukeredzi, T. G., \& Mandrona, A. R. (2013). The journey to becoming professionals: Student teachers' experiences of teaching practice in a rural South African context. International Journal of Educational Research, 62(2013), 141-151.

Ohta, A. (2001). Second language acquisition processes in the classroom: Learning Japanese. Mahwah, NJ: Lawrence Erlbaum Associates.

Richards, J. C., \& Crookes, G. (1988). The practicum in TESOL. TESOL Quarterly, 21, 9-27.

Rodgers, A., \& Keil, V. L. (2007). Restructuring a traditional student teacher supervision model: Fostering enhanced professional development and mentoring within a professional development school context. Teaching and teacher education, 23(1), 63 80.

Saldaña, J. (2015). The coding manual for qualitative researchers. Thousand Oaks, CA: Sage Publication.

Svojanovsky, P. (2017). Supporting student teachers' reflection as a paradigm shift process. Teaching and Teacher Education, 66, 338-348.

Tuli, F. (2009). Understanding undergraduate students practicum experience: A qualitative case study of JIMMA University. Journal of Education and Science, 5(1), 37-61.

Turuk, M. (2008). The relevance and implications of Vygotsky's sociocultural theory in the second language classroom. ARECLS, 5(1), 244-262.

Valencia, J. A. Á. (2009). An exploration of Colombian EFL teachers'knowledge base through teachers ' reflection. Linguagem \& Ensino, 12(1), 73-108.

Valencia, S. W., Martin, S. D., Place, N. A., \& Grossman, P. (2009). Complex interactions in student teaching: Lost opportunities for learning. Journal of Teacher Education, 60(3), 304-322.

Van Lier, L. (1996). Interaction in the language curriculum. Harlow: Longman

Van Lier, L. (2004). The ecology and semiotics of language learning. New York: Kluwer Academic Publishers.

Vygotsky, L.S. (1978). Mind in society. The development of higher psychological processes. Cambridge, MA: Harvard University Press.

Vygotsky, L. S. (1986). Thought and language (A. Kozulin, Trans.). Cambridge,MA: The MIT Press.

Wallace, M. (1991). Training foreign language teachers: A reflective approach. Cambridge University Press, Cambridge, United Kingdom.

Weiss, E. M., \& Weiss, S. (2001). Doing reflective supervision with student teachers in a professional development school culture. Reflective Practice, 2(2), 125-154.

Wertsch, J. V. (1991). Voices of the mind: A sociocultural approach to mediated action. Cambridge, MA: The Harvard University Press.

Wilson, E. K. (2006). The impact of an alternative model of student teacher supervision: Views of the participants. Teaching and teacher education, 22(1), 22-31.

White, S. (2007). Investigating effective feedback practices for pre-service teacher education students on practicum. Journal of Teacher Education, 18(4), 299-311.

Yassin, A. A., Razak, N. A., \& Maasum, T. N. R. T. M. (2019). Integrated Model for Teaching Language Skills. International Journal of English Linguistics, 9(5).

Yin, R. K. (2009). Case study research, design and methods ( $4^{\text {th }}$ ed.). United States of America: Sage Publications.

Zeichner, K. (2010). Rethinking the connections between campus courses and field experiences in college-and university-based teacher education. Journal of teacher education, 61(1-2), 89-99. 


\section{$\underline{\text { AUTHORS'BIOS }}$}

Dr. Morshed Salim Al-Jaro is an Assistant Professor of TESL at the Department of English, Seiyun University, Hadhramout, Yemen. He is currently Head of Department of English, College of Open Education, Seiyun University, Hadhramout, Yemen. He holds a PhD in TESL from the Department of Language and Literacy Education, Faculty of Education, University of Malaya, Malaysia. His main areas of interest include TESL, teacher training, supervision and reflective practice.

https://orcid.org/0000-0002-7755-1156.

Corresponding author

Department of English, Seiyun University, Seiyun, Hadhramout, Yemen

maljaro@seiyunu.edu.ye

Mobile phone: +967777795296

Prof. Dr. Adelina Asmawi is currently the Head of Department of Language and Literacy Education, Faculty of Education, University of Malaya, Malaysia. She holds a PhD in Professional Development of Teachers, TESOL, and Instructional Technology from University of Melbourne, Australia. She actively publishes in the areas of higher education, instructional technology, creative thinking, TESOL and professional development.

https://orcid.org/0000-0003-0595-2986.

Department of Language and Literacy Education, Faculty of Education, University of Malaya, 50603 Kuala Lumpur, Malaysia

Dr. Abdul-Qader Khleel Abdul-Ghafour obtained a PhD in Linguistics from the Sustainability of Language Sciences Research Center, Faculty of Social Sciences and Humanities, Universiti Kebangsaan Malaysia (UKM). He currently works as an Assistant Professor of Linguistics at Queen Arwa University, Sana'a, Yemen. He also works as a freelance translator, editor, and writing consultant. His research interests include translation, semantics, pragmatics, discourse analysis and TEFL/TESOL. 